\title{
Observational analysis on inflammatory reaction to talc pleurodesis: Small and large animal model series review
}

\author{
JACOPO VANNUCCI $^{1}$, GUIDO BELLEZZA ${ }^{2}$, ALBERTO MATRICARDI ${ }^{1}$, GIULIA MORETTI ${ }^{3}$, \\ ANTONELLO BUFALARI $^{3}$, LUCIO CAGINI ${ }^{1}$, FRANCESCO PUMA ${ }^{1}$ and NICCOLÒ DADDI ${ }^{4}$ \\ ${ }^{1}$ Department of Thoracic Surgery; ${ }^{2}$ Institute of Pathological Anatomy and Histology, University of Perugia Medical \\ School; ${ }^{3}$ Department of Veterinary Medicine, University of Perugia, I-06134 Perugia; ${ }^{4}$ Thoracic Surgery, Department \\ of Medical and Surgical Sciences (DIMEC), Alma Mater Studiorum, University of Bologna, I-40126 Bologna, Italy
}

Received April 26, 2017; Accepted September 20, 2017

DOI: $10.3892 / \mathrm{etm} .2017 .5454$

\begin{abstract}
Talc pleurodesis has been associated with pleuropulmonary damage, particularly long-term damage due to its inert nature. The present model series review aimed to assess the safety of this procedure by examining inflammatory stimulus, biocompatibility and tissue reaction following talc pleurodesis. Talc slurry was performed in rabbits: $200 \mathrm{mg} / \mathrm{kg}$ checked at postoperative day 14 (five models), $200 \mathrm{mg} / \mathrm{kg}$ checked at postoperative day 28 (five models), $40 \mathrm{mg} / \mathrm{kg}$, checked at postoperative day 14 (five models), $40 \mathrm{mg} / \mathrm{kg}$ checked at postoperative day 28 (five models). Talc poudrage was performed in pigs: $55 \mathrm{mg} / \mathrm{kg}$ checked at postoperative day 60 (18 models). Tissue inspection and data collection followed the surgical pathology approach currently used in clinical practice. As this was an observational study, no statistical analysis was performed. Regarding the rabbit model (Oryctolagus cunicoli), the extent of adhesions ranged between 0 and 30\%, and between 0 and $10 \%$ following 14 and 28 days, respectively. No intraparenchymal granuloma was observed whereas, pleural granulomas were extensively encountered following both talc dosages, with more evidence of visceral pleura granulomas following $200 \mathrm{mg} / \mathrm{kg}$ compared with $40 \mathrm{mg} / \mathrm{kg}$. Severe florid inflammation was observed in $2 / 10$ cases following $40 \mathrm{mg} / \mathrm{kg}$. Parathymic, pericardium granulomas and mediastinal lymphadenopathy were evidenced at 28 days. At 60 days, from rare adhesions to extended pleurodesis were observed in the pig model (Sus Scrofa domesticus). Pleural granulomas were ubiquitous on visceral and parietal pleurae. Severe spotted
\end{abstract}

Correspondence to: Dr Jacopo Vannucci, Department of Thoracic Surgery, University of Perugia Medical School, Loc. Sant'Andrea delle Fratte, Pz.le Menghini 1, I-06134 Perugia, Italy

E-mail: jacopovannucci@tiscali.it

Key words: pleurodesis, talc, pleural disease, malignant effusion, pleuropulmonary, slurry, poudrage, pneumothorax, animal model, pleuritis inflammation among the adhesions were recorded in $15 / 18$ pigs. Intraparenchymal granulomas were observed in $9 / 18$ lungs. Talc produced unpredictable pleurodesis in both animal models with enduring pleural inflammation whether it was performed via slurry or poudrage. Furthermore, talc appeared to have triggered extended pleural damage, intraparenchymal nodules (porcine poudrage) and mediastinal migration (rabbit slurry).

\section{Introduction}

Talc (Mg3(Si2O5)2(OH)2) is the most commonly used pleurodesis agent worldwide due to its reported success rate especially for malignant pleural effusion (1). Prior to this, talc powder underwent an evolution over the decades in terms of depuration, particle size selection and production refining (2,3). Despite this, the safety of talc remains debatable in terms of local reactions and systemic syndromes such as ARDS. Being so, there is no consensus on whether it should be used for pleurodesis, especially in benign disease $(4,5)$.

To date, most studies on humans have focused on assessing the clinical outcome exclusively, therein reporting only on short-term complications (often in severely symptomatic patients from a respiratory disease) while investigations on long-term complications have been few and mostly describing single cases (6-8). Limited available data on possible long term complications associated with talc pleurodesis are available in the Literature $(2,3,5,6)$.

For the above, since experimental talc pleurodesis series were performed in rabbit and porcine models, belonging to independent experimental comparative studies, carried out by the same research group and using medical talc in different animal models, different dosages and distinctive surgical techniques, an observational model series review was performed to report the findings after this extended experience with talc. The aim of this analysis was to generate hypothesis regarding the functional profile of talc for pleurodesis. Therefore, talc biocompatibility, pleural reaction to talc deposition on the mesothelium, intrapulmonary and lymphatic spread are observed to highlight possible unknown events. 


\section{Materials and methods}

This analysis of talc pleurodesis was performed as a secondary investigation (opportunistic study) analysing animal models series undergoing talc pleurodesis and belonging to already performed experimental research protocols (9-11). Talc slurry was performed in rabbits in different dosages with the aim to compare talc to antibiotic both at increasing concentration and administered via chest tube. The chosen dosages of talc were therefore arbitrary and sought to see differences in performance of talc at marked dose variation at different postoperative time. Besides, talc poudrage was performed at standard dosage in pigs for the impossibility to simulate an appropriate surgical surrogate for medical thoracoscopy in a smaller animal model. Moreover, some differences in the experimental techniques between the rabbit and the swine series depend on the study aims and designs.

Animal management was carried out following recommended practices pertaining to animal laboratory research $(12,13)$. The protocol was approved by central and local authorities for animal care. Talc poudrage and slurry were tested using a commonly available depurated, calibrated preparation (Sterital, La Ciotat, France) in the following models/methodology.

Rabbit model-talc slurry: Twenty New Zealand White rabbits (Oryctolagus cuniculi), 7 weeks old, mean 2,450 g, (range: $2,100-2,450 \mathrm{~g}$ ) were submitted to talc slurry and divided into 4 groups according to the following scheme: $200 \mathrm{mg} / \mathrm{kg}$, checked at postoperative day 14 (5 models); $200 \mathrm{mg} / \mathrm{kg}$, checked at postoperative day 28 (5 models); $40 \mathrm{mg} / \mathrm{kg}$, checked at postoperative day 14 (5 models); $40 \mathrm{mg} / \mathrm{kg}$, checked at postoperative day 28 (5 models).

The procedure was performed under general anaesthesia. A $10 \mathrm{fr}$ intrapleural catheter was placed time of surgery. Talc suspended in $2 \mathrm{ml}$ saline was administered through the chest tube; pneumothorax was eliminated by syringe suction. The drain was locked for $24 \mathrm{~h}$ then left open until post-operative day 4 , when it was removed.

Swine model-talc poudrage: Eighteen Landrance x Large White pigs (Sus Scrofa domesticus), 4 months old, mean $42.7 \mathrm{~kg}$, (range: $40-45 \mathrm{~kg}$ ), were submitted to uniportal videothoracoscopy (VATS) using the same procedure for human care in each technical detail. Talc was sprayed and checked for homogenous deposit all over the pleural surface before ending the procedure. Complete resolution of pneumothorax was achieved under monitor view. No chest tube was left in place. Talc poudrage was performed according to the following design: $55 \mathrm{mg} / \mathrm{kg}$, checked at postoperative day 60 (18 models).

All models were analyzed post-mortem after painless euthanasia. Autopsy was carried out according to the current medical technique with inspection of all anatomical spaces and cavities, systematically carried out following a standardized and repeatable procedure. Description of findings and pictures were performed by circulating members of the team. Autopsy operator followed a predetermined routine in dissection and samples collection, did not analyze the findings and was not involved in interpretation of data. Observation sought to estimate the extent of adhesions, pleural granulomas, intraprenchymal granulomas, and severe spotted inflammation without pleurodesis. After autoptic assessment, the pathologist and the surgeon evaluated the specimens with a teamwork approach. Macroscopic examination and microscopic assessment were systematically carried out according to the current clinical surgical pathology methodology. Considering the descriptive objective of the paper, no statistical analysis was applied to the numerical variables.

\section{Results}

The outcome of talc pleurodesis in rabbits (talc slurry) is reported in Tables I and II; the outcome of talc pleurodesis in pigs (talc poudrage) is summarized in Table III. The extent of the adhesions observed in rabbits after 14 days from $40 \mathrm{mg} / \mathrm{kg}$ talc slurry ranged from 0 to $30 \%$ of the pleural surface with no intraparenchymal granulomas, but frequent parietal pleura granulomas. Pleural granulomas were observed in all rabbits, whereas severe florid inflammation without pleurodesis was recorded in one case after 14 days. When this talc dosage was tested at 28 days, the range of pleurodesis extent resulted being between 0 and $10 \%$ of the pleural cavity with no intraperinchymal granuloma and only one case of florid inflammatory event of the pleura without pleurodesis. In the series of rabbits undergoing $200 \mathrm{mg} / \mathrm{kg}$ talc slurry, the extent of pleurodesis did not appear to increase dramatically (range from 0 to $10 \%$ at postoperative day 14 , and 0 to $20 \%$ at postoperative day 28) with no intraparenchymal granuloma and no florid spotted pleural inflammation. For this series of rabbits, granulomas on the outer pericardium (seen on postoperative day 14), an isolated mediastinal lymphadenopathy below the main carina and an isolated parathymic granuloma (seen on postoperative day 28) were observed. Representative findings are shown in Fig. 1.

The series of pigs undergoing $55 \mathrm{mg} / \mathrm{kg}$ talc poudrage (uniportal VATS) had a wide range of outcomes regarding the extent of pleurodesis achieved after a post-operative period of 60 days. The outcome ranged from rare adhesions with no symphysis to a single case with a complete pleurodesis characterized by a fully extended pleural cavity obliteration. Pleural granulomas were observed in the entire series of the swine models, both visceral and parietal. Autopsies revealed severe spotted inflammation in sites of the pleural surface without pleurodesis in 15/18 pigs. Systematic sampling was performed at the bench and intraparenchymal granulomas were observed in 9/18 lungs. Patterns of disease post-talcing are shown in Fig. 2. Histologies of exemplifying findings are provided in Fig. 3.

\section{Discussion}

Talc is the most used sclerosing agent worldwide for achieving pleural space obliteration. Though its efficacy has been widely reported especially in neoplastic effusion, severe inflammatory reactions have been described both acute and long-term (14-16). For this, an analysis in animal models was carried out to investigate for the local reaction following the contact of talc powder on the pleura. The materials under investigation show interesting potentials considering that talc pleurodesis was performed in different animal models, 
Table I. Talc slurry (40 mg/kg) in rabbits (10 Fr pleural catheter).

14 days postoperative observation

\begin{tabular}{lccccc}
\hline No. & Adhesions & Pleural granuloma & $\begin{array}{c}\text { Intraparenchymal } \\
\text { granuloma }\end{array}$ & $\begin{array}{c}\text { Severe spotted inflammation } \\
\text { without pleurodesis }\end{array}$ & Note \\
\hline 1 & YES $<5 \%$ & YES parietal & NO & NO & None \\
2 & YES $<30 \%$ & YES parietal & NO & NO & NO \\
3 & YES $<10 \%$ & YES parietal & NO & YES & None \\
4 & NO & YES parietal & NO & NO & None \\
5 & NO & YES parietal & NO & & Fibrosis \\
\hline
\end{tabular}

28 days postoperative observation

Table II. Talc slurry (200 mg/kg) in rabbits (10 Fr pleural catheter).

14 days postoperative observation

Intraparenchymal Severe spotted inflammation

\begin{tabular}{lclccc} 
No. & Adhesions & Pleural granuloma & granuloma & without pleurodesis & Note \\
\hline 1 & NO & NO & NO & YES & None \\
2 & YES $<10 \%$ & NO & NO & NO & NO \\
3 & YES $<10 \%$ & NO & NO & NO & None \\
4 & YES $<5 \%$ & YES visceral & NO & NO & None \\
5 & YES $<5 \%$ & YES parietal & NO & &
\end{tabular}

\begin{tabular}{lclccc}
\hline No. & Adhesions & Pleural granuloma & $\begin{array}{c}\text { Intraparenchymal } \\
\text { granuloma }\end{array}$ & $\begin{array}{c}\text { Severe spotted inflammation } \\
\text { without pleurodesis }\end{array}$ & Note \\
\hline 1 & YES $<5 \%$ & YES visceral/parietal & NO & NO & None \\
2 & YES $<10 \%$ & YES visceral & NO & NO & None \\
3 & YES $<5 \%$ & YES visceral/parietal & NO & NO & Pericardium granulomas \\
4 & NO & YES visceral & NO & NO & None \\
5 & NO & YES visceral & NO & & None \\
\hline
\end{tabular}

28 days postoperative observation

\begin{tabular}{|c|c|c|c|c|c|}
\hline No. & Adhesions & Pleural granuloma & $\begin{array}{l}\text { Intraparenchymal } \\
\text { granuloma }\end{array}$ & $\begin{array}{l}\text { Severe spotted inflammation } \\
\text { without pleurodesis }\end{array}$ & Note \\
\hline 1 & $\mathrm{NO}$ & YES visceral/parietal & $\mathrm{NO}$ & NO & $\begin{array}{l}\text { Lymphadenopathy } \\
\text { (main carina) }\end{array}$ \\
\hline 2 & YES $<5 \%$ & YES visceral/parietal & $\mathrm{NO}$ & $\mathrm{NO}$ & None \\
\hline 3 & $\mathrm{YES}<5 \%$ & YES visceral/parietal & $\mathrm{NO}$ & NO & None \\
\hline 4 & YES $<20 \%$ & YES visceral & $\mathrm{NO}$ & $\mathrm{NO}$ & None \\
\hline 5 & YES $<20 \%$ & YES parietal & NO & NO & Parathymic granuloma \\
\hline
\end{tabular}

alternative techniques and dosages. The available dataset represents a unique source of information for a single research group according to accessible Literature.

Talc pleurodesis is generally a technique supporting another procedure such as videothoracoscopy or chest drainage with several aspects of perfectibility (17). Any assessment of talc-related effects is complex in clinical research, so an experimental setting appears to be the only currently available way to evaluate biocompatibility, pleural reaction and any subsequent damage. For this animal series review, talc 
Table III. Talc poudrage $(55 \mathrm{mg} / \mathrm{kg})$ in pigs (single-port videothoracoscopy).

60 days postoperative observation

\begin{tabular}{cccccc}
\cline { 2 - 5 } No. & Adhesions $(\%)$ & Pleural granuloma & $\begin{array}{c}\text { Intraparenchymal } \\
\text { granuloma }\end{array}$ & $\begin{array}{c}\text { Severe spotted inflammation } \\
\text { without pleurodesis }\end{array}$ & Note \\
\hline 1 & YES $<5$ & Yes visceral/parietal & NO & YES & None \\
2 & YES $<15$ & Yes visceral/parietal & NO & NO & None \\
3 & YES $<5$ & Yes visceral/parietal & YES & YES & None \\
4 & YES $<50$ & Yes visceral/parietal & NO & YES & None \\
5 & YES $<50$ & Yes visceral/parietal & NO & YES & None \\
6 & YES $<5$ & Yes visceral/parietal & YES & YES & NO \\
7 & YES $>50$ & Yes visceral/parietal & YES & YES & None \\
8 & YES $<20$ & Yes visceral/parietal & YES & YES & None \\
9 & YES $<20$ & Yes visceral/parietal & NO & YES & None \\
10 & YES $<25$ & Yes visceral/parietal & YES & YES & None \\
11 & YES $<5$ & Yes visceral/parietal & YES & YES & None \\
12 & YES $<15$ & Yes visceral/parietal & NO & YES & None \\
13 & YES $<20$ & Yes visceral/parietal & NO & YES & None \\
14 & YES $<20$ & Yes visceral/parietal & YES & YES & None \\
15 & YES $<25$ & Yes visceral/parietal & NO & NO & None \\
16 & YES $<25$ & Yes visceral/parietal & NO & YES & None \\
17 & YES $<50$ & Yes visceral/parietal & YES & YES & None \\
18 & YES $<15$ & Yes visceral/parietal & YES & &
\end{tabular}
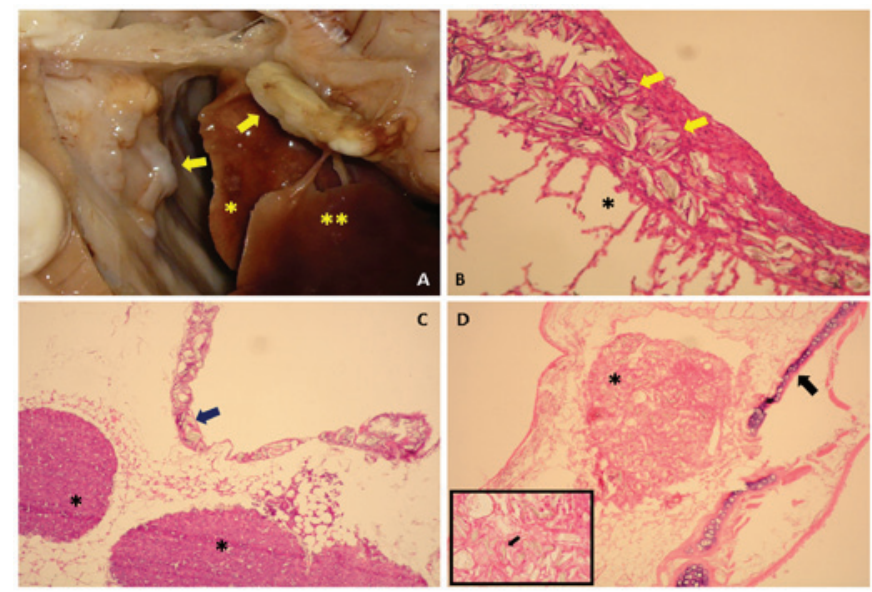

Figure 1. (A) Macroscopic appearance of the intrapleural rabbit space. The talc deposits (yellow arrows) were evident on the parietal and diaphragmatic pleura as well as few visceral granulomas (yellow asterisk) with pleura adhesions (double yellow asterisks) were identified. (B) Talc crystals (yellow arrows) were encased in the visceral pleura with mild intra-alveolar inflammatory response (x20 magnification, hematoxylin and eosin staining). (C) Talc crystals deposits (arrow) were identified in the mediastinal pleura with concomitant inflamed lymphnodes (asterisks) present in the surrounding fat pad (10X magnification, hematoxylin-eosin staining). (D) Subcarinal (arrow shows the cartilaginous part of the main airway, x10 magnification, hematoxylin-eosin staining) lymphnode (asterisk) with talc crystal deposits (framed figure, arrow, x20 magnification, hematoxylin and eosin staining).

was administered either poudrage or slurry in two different well-established animal models, pigs and rabbits, respectively.

When talc was administered slurry in rabbit pleural cavities, the obliteration of space never exceeded $30 \%$ of the entire pleural cavity surface. Whereas, poudrage outcome in the swine models varied from 0 to $100 \%$, so that the effect of talc poudrage cannot have allowed for an accurate prediction of outcome after a videothoracoscopic administration of depurated, dry, sterilized talc. In rabbits, intrapulmonary granulomas were infrequent, while they were a common finding in the pig series. According to published case reports, the intraparenchymal deposit of talc could even provoke a high metabolic activity (18). The results from our model series analysis evidenced that talc-related events were common. Likewise, the exploration of the pleural cavities post-mortem evidenced that severe inflammation often afflicted the pleural layer without pleurodesis: noxa without effects.

The observation surprisingly evidenced some possible differences between models or surgical techniques. Specifically, there is no gross evidence of intraparenchymal granulomas after slurry in rabbits while it is a common finding in porcine poudrage. Besides, there is no particular mediastinal involvement after poudrage in pigs while high dose of talc slurry was associated with possible mediastinal migration and deposition of talc in extended granulomas. The study design is not able to explain these differences and does not allow for a fine comparison between techniques but supports some hypothesis regarding different outcome due to pleurodesis procedure as already suggested after clinical research (19). Many questions on what these differences are dependent on arise but they necessitate further specific studies with comparative design to experimentally test different dosages, slurry vs. poudrage, differences between the animal models and model-dependent variability for the procedure outcome. Nevertheless, the 


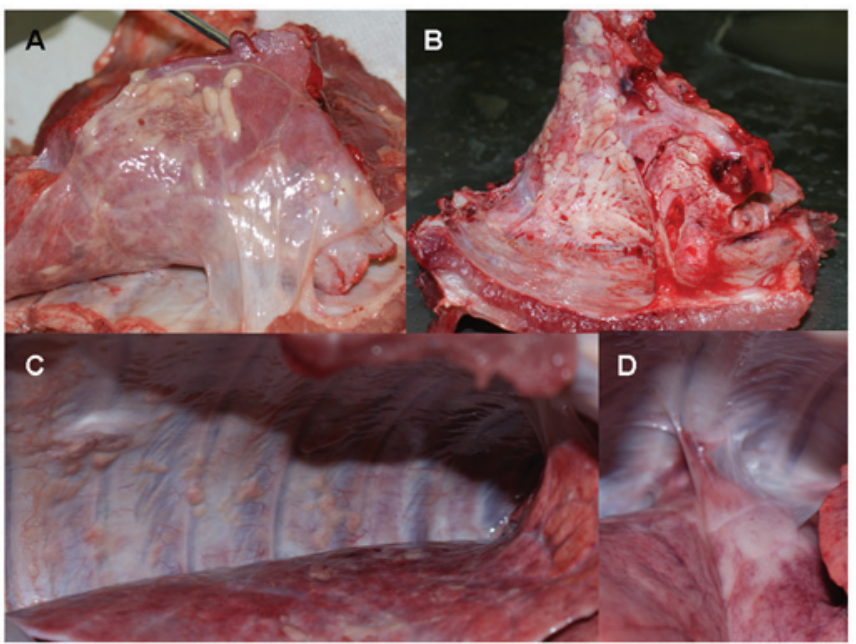

Figure 2. (A) A sparse adhesion with diffuse visceral pleura thickening and dullness. Lung parenchyma appears diffusely congested. Talc accumulation with pleural whitish soft reactive nodules are present (arrow). (B) Stronger pleurodesis reaction compared to A with much more evident pleural thickening and superficial talc accumulation (arrow). Significant blood supply of the area with consistent neoangiogenesis within the reactive tissue forming the adhesion. (C) Diffuse nodular pleuritis of both visceral and parietal pleurae (arrow) without any significant pleurodesis (damage without effect) (D) Isolated pleural adhesion with important lung parenchyma reaction: diffuse whitening of the parenchyma with palpable consolidation (arrow).

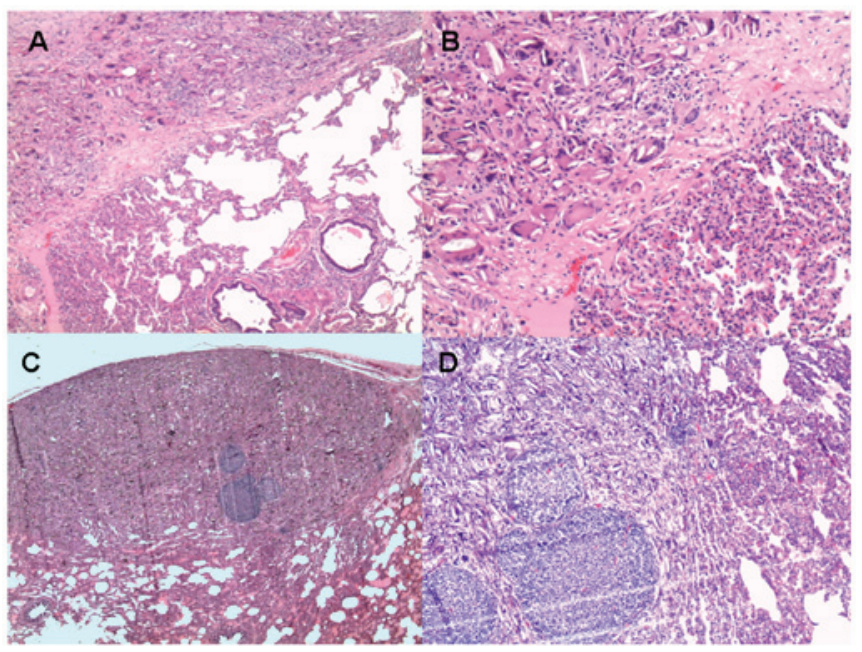

Figure 3. (A) Lung parenchyma shows area of atelectasis along with airspace enlargement in the lower part of the image and, in the upper part, a wide granulomatous reaction rich in foreign-body giant cells (arrow); haematoxylin and eosin staining, x100 magnification. (B) Foreign-body giant cells contain irregular pale-yellow talc particles that are strongly birefringent (arrow); haematoxylin and eosin staining, x400 magnification (C) A subpleural intraparenchymal nodule consisting of a granulomatous reaction with many foreign-body giant cells admixed with early collagen tissue deposition (arrow); haematoxylin and eosin, x100 magnification. (D) In details, lymphatic reactive follicles with germinal centers are shown consisting with a strong host immune reaction (arrow); haematoxylin and eosin, x250 magnification.

pleurodesis outcome is associated with very variable results independently in all the animal series reviewed in this analysis.

Past controversies concerned the safety and severity of this procedure, specifically its possible reaction to dose, type of management and the particle size (20). The marked variations among these preparations were claimed to produce systemic inflammatory complications, molecule migration modalities and other effects such as acute lung injuries (21). Whereas, the most currently used talc preparations are standardized. In published studies to date on talc safety, especially those carried out over the 20th century, the preparation of talc was not usually well described and there was a lack of information regarding particles size, as well as degree of contamination (16).

As talc can cause damage when inhaled or after intravenous administration leading to granulomatosis, organ consolidation, deposition in parenchyma and diffuse pulmonary diseases $(22,23)$, its use has been associated with acute lung injuries and its systemic absorption (24). Predictors of acute responses to talc pleurodesis have been hypothesised and different procedures for a safer administration have been developed $(19,20)$. Acute events have been reported following pleurodesis including: fever, chest pain, hypoxemia, dyspnea, hypotension, lipothymia and less commonly hypercalcemia along with acute respiratory distress syndrome (25). As well, chronic events have also been reported including granulomas, pleural thickening, mesotheliod reaction and pulmonary nodules $(6-8,26)$.

Despite concerns regarding the long-term consequences of talc in young patients, its use is on the rise, even for benign diseases as primary spontaneous pneumothorax (27). Nonetheless, recent experimental research in a mouse model, although reporting decreased effusion, concluded that there was an observed limited pleurodesis surface with marked pleural thickening following this procedure (28).

Our animal model series review had limitations. First, there was no comparative set up, unless for dosages in talc slurry, and it was based upon simple observation. Second, the animal series were extracted out of different protocols for a secondary scientific purpose; two different animal models and two different talc pleurodesis procedures were used and this might have led to a bias in the final results regarding the evaluation of effectiveness and reliability of talc action.

In conclusion, despite pleurodesis being one of the most requested procedures for the treatment of many systemic and thoracic diseases, there is still no consensus on which situation it is best suited for. Our study assessed for inflammatory stimulus, biocompatibility and tissue reaction in animal models and found that talc pleurodesis led to pleuropulmonary granulomas especially after poudrage in pigs, intrathoracic migration and diffuse pleural thickening. These findings suggest that talc was not an 'ideal' agent due to the observed chronic inflammatory patterns following the procedure, which could potentially have long term effects. In this regard, research must focus on biomedical properties of existing products to extend indications for use once they are tested for reliability, safety and risk/effectiveness while experimental research should aim at creating a new sclerosing agent with all those biochemical and functional traits to perform the ideal pleurodesis.

\section{Acknowledgements}

The study was reviewed for language editing by English language Service. 


\section{References}

1. Janssen JP, Collier G, Astoul P, Tassi GF, Noppen M, Rodriguez-Panadero F, Loddenkemper R, Herth FJ, Gasparini S, Marquette $\mathrm{CH}$, et al: Safety of pleurodesis with talc poudrage in malignant pleural effusion: A prospective cohort study. Lancet 369: 1535-1539, 2007.

2. Baron RD, Milton R and Thorpe JA: Pleurodesis using small talc particles results in an unacceptably high rate of acute lung injury and hypoxia. Ann Thorac Surg 84: 2136, 2007.

3. Genofre EH, Vargas FS, Acencio MM, Antonangelo L, Texweira LR and Marchi E: Talc pleurodesis: Evidence of sistemic inflammatory response to small size particles. Respir Med 103: 91-97, 2009.

4. Sahn SA: Talc should be used for pleurodesis. Am J Respir Crit Care Med 162: 2023-2049, 2000.

5. Light RW: Talc should not be used for pleurodesis. Am J Respir Crit Care Med 162: 2024-2026, 2000.

6. Vandemoortele T, Laroumagne S, Roca E, Bylicki O, Dales JP, Dutau H and Astoul P: Positive FDG-PET/CT of the pleura twenty years after talc pleurodesis: Three cases of benign talcoma. Respiration 87: 243-248, 2014.

7. Ergönül AG, Çakan A, Çağirici U and Nart D: Talc granulomatosis with multiple parenchymal and pleural nodules. Eur J Cardiothorac Surg 44: e308, 2013.

8. Tenconi S, Luzzi L, Paladini P, Voltolini L, Gallazzi MS, Granato F and Gotti G: Pleural granuloma mimicking malignancy 42 years after slurry talc injection for primary spontaneous pneumothorax. Eur Surg Res 44: 201-203, 2010.

9. Daddi N, Vannucci J, Maggio C, Giontella A, Bravi I, Marziani F, Capozzi R, Ragusa M, Bufalari A and Puma F: Efficacy of tigecycline pleurodesis: A comparative experimental study. J Surg Res 169: e109-e118, 2011.

10. Droghetti A, Vannucci J, Bufalari A, Bellezza G, De Monte V, Marulli G, Bottoli MC, Giovanardi M, Daddi N, De Angelis V, et al: Pleurodesis with Thulium Cyber Laser versus talc poudrage: A comparative experimental study. Lasers Med Sci 31: 1407-1413, 2016.

11. Vannucci J, Droghetti A, Bufalari A, De Monte V, Bellezza G, Bianconi F, Pecoriello R, Daddi N, Moriconi F and Puma F: Effectiveness and predictability of pleurodesis with the Tachosil ${ }^{\circledR}$ surgical patch compared with talc poudrage: An experimental study. Eur J Cardiothorac Surg 50: 668-9674, 2016.

12. Suckow MA, Schroeder V and Douglas FA: The Laboratory Rabbit. 2nd edition. CRC Press, Taylor, Francis Group, London, 2010.

13. Bufalari A, De Monte V, Pecoriello R, Donati L, Ceccarelli S, Cagini L, Ragusa M and Vannucci J: Experimental left pneumonectomy in pigs: Procedure and management. J Surg Res 198 208-216, 2015 .

14. Genofre HG, Marchi E and Vargas FS: Inflammation and clinical repercussions of pleurodesis induced by intrapleural talc administration. Clinics (Sao Paulo) 62: 627-634, 2007.
15. West SD, Davies RJ and Lee YC: Pleurodesis for malignant pleural effusions: Current controversies and variations in practices. Curr Opin Pulm Med 10: 305-310, 2004

16. Aelony Y: Talc pleurodesis and acute respiratory distress syndrome. Lancet 369: 1494-1496, 2007.

17. Porcel JM, Lui MM, Lerner AD, Davies HE, Feller-Kopman D and Lee YC: Comparing approaches to the management of malignant pleural effusions. Expert Rev Respir Med 11: 273-284, 2017.

18. Kurian EM: Lung nodule with increasing fluorodeoxyglucose uptake in a patient with a history of lung carcinoma and talc pleurodesis evaluated by EBUS-TBNA on-site assessment. Acta Cytol 61: 84-86, 2017.

19. Stefani A, Natali P, Casali C and Morandi U: Talc poudrage versus talc slurry in the treatment of malignant pleural effusion. A prospective comparative study. Eur J Cardiothoracic Surg 30: 827-832, 2006.

20. Light RW: Talc for Pleurodesis? Chest 122: 1506-1508, 2002.

21. Baron RD, Milton R and Thorpe JAC: Pleurodesis using small talc particles results in an unacceptably high rate of acute lung injury and hypoxia. Ann Thorac Surg 84: 2136, 2007.

22. Iqbal A, Aggarwal B, Menon B and Kulshreshtha R: Talc granulomatosis mimicking sarcoidosis. Singapore Med J 49: e168-e170, 2008

23. Fiorelli A, Accardo M, Rossi F and Santini M: Spontaneous pneumothorax associated with talc pulmonary granulomatosis after cocaine inhalation. Gen Thorac Cardiovasc Surg 64: 174-176, 2016.

24. Lee YC and Light RW: Management of malignant pleural effusions. Respirology 9: 148-156,2004.

25. Aujila SJ, Michelson P, Langman CB, Shapiro R, Ellis D and Moritz ML: Refractory hypercalcemia in an infant secondary to talc pleurodesis resolving after renal transplantation. Am J Transplant 8: 1329-1333, 2008.

26. Faynberg T, Patel N, Nayar AP and Shienbaum AJ: Mesothelioid reaction following talc pleurodesis: A case report. Gen Thorac Cardiovasc Surg: Mar 7, 2017 (Epub ahead of print).

27. Cardillo G, Bintcliffe OJ, Carleo F, Carbone L, Di Martino M, Kahan BC and Maskell NA: Primary spontaneous pneumothorax: A cohort study of VATS with talc poudrage. Thorax 71: 847-853, 2016.

28. Iwasaki Y, Takamori S, Mitsuoka M, Kashihara M, Nishi T, Murakami D, Matsumoto R, Mifune H, Tajiri Y and Akagi Y: Experimental validation of talc pleurodesis for carcinomatous pleuritis in an animal model. Gen Thorac Cardiovasc Surg 64: 409-413, 2016.

This work is licensed under a Creative Commons Attribution-NonCommercial-NoDerivatives 4.0 International (CC BY-NC-ND 4.0) License. 